\title{
Chromosome 18q deletion and Smad4 protein inactivation correlate with liver metastasis: a study matched for $T$ - and N- classification
}

\author{
T Tanaka', T Watanabe*,2, Y Kazama', J Tanaka', T Kanazawa', S Kazama' and H Nagawa' \\ 'Department of Surgical Oncology, University of Tokyo, 7-3-I Hongo, Bunkyo-Ku, Tokyo, Japan; ${ }^{2}$ The Department of Surgery, Graduate School of \\ Medicine, Teikyo University, 2-I I-I Kaga, Itabashi-Ku, Tokyo, Japan
}

Smad4 protein, whose gene is coded at chromosome $18 \mathrm{q} 21$. I, is an important tumour suppressor that mediates transforming growth factor-beta. It has been reported that inactivation of the Smad4 gene and allelic loss of chromosome $18 \mathrm{q}$ correlate with liver metastasis and poorer prognosis in colorectal cancers. Utilising a recently developed method of immunohistochemical staining for Smad4 protein, we focused on the specific impact of Smad4 protein expression on liver metastasis in colorectal cancer. We also evaluated the association between chromosomel8q deletion and liver metastasis. We selected 20 colorectal cancers with liver metastasis for the experimental group, and 20 cases without liver metastasis for the control. In order to exclude the influence of lymph node metastasis, all cases were lymph node negative. In addition, the two groups were matched for tumour depth, tumour differentiation and tumour location. We compared the expression level of Smad4 protein immunohistochemically in these 20 matched pairs. We also compared the loss of heterozygosity status at chromosome $18 \mathrm{q}$ in these 20 matched pairs Immunohistochemical staining revealed a significant difference $(P=0.024)$ in the level of Smad4 protein between the two groups. We also observed a significantly different $(P=0.0054)$ ratio of allelic deletion at chromosome I 8q21. Smad4 protein expression level and allelic loss at I8q2I are associated with the process of liver metastasis in colorectal cancers evaluated when excluding clinical and pathological features except for liver metastasis.

British Journal of Cancer (2006) 95, I562 - 1567. doi:I0.1038/sj.bjc.6603460 www.bjcancer.com

Published online 7 November 2006

(C) 2006 Cancer Research UK

Keywords: colorectal cancer; Smad4; I8q; LOH; liver metastasis

Colorectal cancer develops through multistep genetic alterations, involving several oncogene and tumour suppressor genes (Vogelstein et al, 1988, 1989; Benhattar et al, 1993; Kinzler and Vogelstein, 1996; Span et al, 1996; Kambara et al, 2004; Nassif et al, 2004). Loss of heterozygosity ( $\mathrm{LOH})$ is one of the major types of genetic inactivation, and the long arm of chromosome 18 is the most frequently deleted region in colorectal cancers. To date, many reports suggest that this deletion is a molecular predictor that affects survival (Fearon et al, 1990; Jen et al, 1994; Chung, 1998; Lanza et al, 1998; Ogunbiyi et al, 1998; Jernvall et al, 1999; McLeod and Murray, 1999; Sarli et al, 2004). We too reported that the allelic deletion of chromosome 18q was associated with poorer prognosis in stage III colon cancer after adjuvant chemotherapy (Watanabe et $a l, 2001,2006)$. These reports suggest that there might be tumour suppressor genes located at chromosome 18q, which has a strong influence on survival. Smad4 gene, which mediates the intracellular signalling pathway of transforming growth factor (TGF)-beta receptor, has been detected as one of the target genes at 18q21 (Wang et al, 1995; Eppert et al, 1996; Hahn et al, 1996;

* Correspondence: Professor T Watanabe;

E-mail: toshwatanabe@yahoo.co.jp

Received I 8 May 2006; revised I 3 September 2006; accepted 3 October 2006; published online 7 November 2006
Thiagalingam et al, 1996; Carethers et al, 1998; Markowitz, 2000; Fink et al, 2003; Alazzouzi et al, 2005; Li et al, 2005). Recently, an immunohistochemical method for evaluating Smad4 protein has been developed and several studies found higher frequency of Smad4 protein inactivation in the cases with liver metastasis and in the cases presenting unfavourable survival (Maitra et al, 2000; Alazzouzi et al, 2005).

Currently, recurrences of colorectal cancers appear mainly as lymph node metastasis or liver metastasis. This means that both lymph node metastasis and liver metastasis have an influence on survival after surgery. Furthermore, tumour depth and tumour differentiation cannot be ignored when thinking of the malignancy potential of the tumour. However, in all the previous reports discussing the correlation of Smad4 protein and 18q deletion with survival, tumour depth, lymph node metastasis and tumour differentiations were not matched. Under such conditions, it was impossible to detect which of these clinical and pathological features that determine survival were truly associated with Smad4 protein expression and $18 \mathrm{q}$ deletion.

In this report, we attempted to focus on the specific influence of Smad4 protein expression and 18q deletion on the development of liver metastasis. In order to achieve this aim, we selected only lymph node negative cases so as to exclude the influence of lymph node invasion. Furthermore, we match tumour depth, tumour differentiation and tumour locations, which have been reported to 
influence $\mathrm{LOH}$ status and microsatellite instability. To the best of our knowledge, this is the first report to assess the specific impact of Smad4 protein and $18 \mathrm{q}$ deletion on the development of liver metastasis under these conditions, which enabled us to exclude the influence of clinical and pathological features other than liver metastasis.

\section{MATERIALS AND METHODS}

\section{Patient samples}

Specimens were obtained during routine operations at the Department of Surgical Oncology, Tokyo University Hospital, from January 1980 to July 2005. Cases of familial adenomatous polyposis and hereditary nonpolyposis colorectal carcinoma were excluded from this study. No patient received cytotoxic therapy before surgery. The study was approved by the Ethics Committee of Tokyo University Hospital and patients gave their written informed consent for the use of the specimens in advance.

There were 2783 cases of colorectal cancers operated on in our hospital during this period and 261 cases were positive for liver metastasis at the time of surgery. We selected 20 cases out of them, which are confirmed negative for lymph node metastasis.

First, these 20 cases were assigned to the liver-metastasis (+) group. Next, 20 cases negative for liver metastasis and negative for lymph node metastasis were assigned to the liver-metastasis (-) group. The pathological T-classification, tumour location and tumour differentiation of both groups were matched.

The clinical and pathological features of both groups are shown in Table 1. Of the 40 patients in the two groups, 29 were male and 11 were female. The age distribution was from 26 to 79 years. There was no statistically significant difference in the distribution of sex and age between the liver-metastasis $(+)$ and liver-metastasis (-) groups. Pathological staging in each case was according to the UICC/TNM classification. T-classification and tumour differentiation in each group were the same, as follows: T1, one (5\%); T2, one (5\%); T3, 17 (85\%); T4, one (5\%); well-differentiated adenocarcinoma, 19 (95\%); poorly differentiated adenocarcinoma, one (5\%). The distribution of tumour location was also matched in both groups: right colon, two (10\%); left colon, four (20\%); rectum, 14 $(70 \%)$. The mean and median follow-up period were 1438 days and

Table I Clinicopathological features of colorectal carcinomas

\begin{tabular}{lccc}
\hline Group & Liver metastasis (+) & \multicolumn{2}{c}{ Liver metastasis (-) } \\
\hline Age & $61.2 \pm 3.8$ & $57.1 \pm 5.2$ & NS \\
Gender & 15 & 14 & NS \\
Male & 5 & 6 & \\
Female & & 1 & 1 \\
T-classification & 1 & 17 & \\
TI & 1 & & \\
T2 & 17 & 2 \\
T3 & 1 & 4 \\
T4 & & 14 \\
Location & 2 & \\
Right colon & 4 & 19 \\
Left colon & 14 & 0 \\
Rectum & & 1 \\
Differentiation & 19 & \\
Well & 0 & & \\
Moderately & 1 & & \\
Poorly & & & \\
\hline
\end{tabular}

Liver metastasis (-): a group of tumours without liver metastasis. Liver metastasis (+): a group of tumours with liver metastasis.
1014 days for liver-metastasis (-), during which no case of livermetastasis (-) has been confirmed not to experience recurrence.

\section{Immunohistochemical staining}

All the samples for immunohistochemical analysis were obtained from paraffin-embedded specimens. Serial sections were cut at a thickness of $3 \mu \mathrm{m}$ for both Smad4 immunostaining and haematoxylin-eosin (H\&E) staining.

The sections were deparaffinized with xylene and dehydrated with $98 \%$ ethanol, placed in $0.01 \mathrm{~m}$ sodium citrate buffer ( $\mathrm{pH} 6.0$ ), and heated in a microwave oven for three 7 -min cycles $(500 \mathrm{~W})$. After washing three times in PBS, endogeneous peroxidase activity was inhibited by incubation with $0.3 \%$ hydrogen peroxide in methanol for $20 \mathrm{~min}$. Biotinylated rabbit anti-mouse immunoglobulin and SAB complex which were supplied commercially (Histofine SAB-PO(M) kit, Nichirei, Tokyo, Japan) were used as reagents for the next step. The sections were incubated overnight at a temperature of $-4^{\circ} \mathrm{C}$ with anti-SMAD4 monoclonal antibody (Smad4(B-8):sc-7966, Santa Cruz Biotechnology, Inc., CA, USA) at a dilution of $1: 1000$. Colour was then developed with diaminobenzidine solution. Sections were then lightly counterstained with a cocktail of Mayer's/Lillie-Mayer's haematoxyline and mounted.

\section{Evaluation of Smad4 immunostaining}

All the specimen immunostained for Smad4 protein were evaluated without knowing their clinicopathological features. Smad4 staining was predominantly observed in cytoplasm.

All the normal mucosa showed immunohistochemical staining against Smad4 protein. The samples were evaluated as reported previously (Alazzouzi et al, 2005). To evaluate the intensity of Smad4 immunohistochemical staining, we used a semiquantitative scale, where $0=$ no Smad 4 staining and 4 was the highest staining. The samples that stained as strong as normal mucosa were scored as 4 , whereas the samples with no detectable immunohistochemical staining were scored as zero. The grades of the remaining weakly and partially stained samples were classified as previously reported (Iacobuzio-Donahue et al, 2000). The samples in which all the tumour cells showed positive but weaker stain than the normal mucosa were scored as 3 . And the samples that showed diffuse stain were scored as 2 , whereas the samples that showed focal stain were scored as 1 .

For statistical analysis, we classified these scores into three groups: (1) no Smad4 (scored 0), (2) low Smad4 (scored 1 to 3) and (3) high Smad4 (scored 4). Representative samples of Smad4 staining are shown in Figure 1.

\section{Analysing the status of $\mathrm{LOH}$}

From the liver-metastasis $(+)$ and liver-metastasis (-) groups, 12 T-matched pairs of tumours were available from their primary frozen specimens. These specimens were used for $\mathrm{LOH}$ analysis. The samples were snap-frozen in liquid nitrogen immediately after being resected during routine operations and stored at $-80^{\circ} \mathrm{C}$ until the DNA was extracted from each specimen using DNAeasy kit (Qiagen, Tokyo, Japan). From other eight T-matched pair of samples whose frozen specimens were not stored, we also obtained DNA from paraffine-embedded specimens by microdissection techniques as we described in the previous report (Kazama et al, 2006), resulting in obtaining all the 20 T-matched pairs of samples in this $\mathrm{LOH}$ analysis.

To detect allelic loss, we employed three polymorphic markers; D18s363, D18s474 and D18s46, mapped closely to Smad4 locus. The primer sequences were obtained at the Genome Database. The locations of the primers are shown in Figure 2. The sequence of each primer is as follow: D18s363: $5^{\prime}$-TTGGGAACTGCTCTA CATTC-3' (sense), 5'-GCTTCATTCTCTCACTGGAT-3' (antisense); 
A
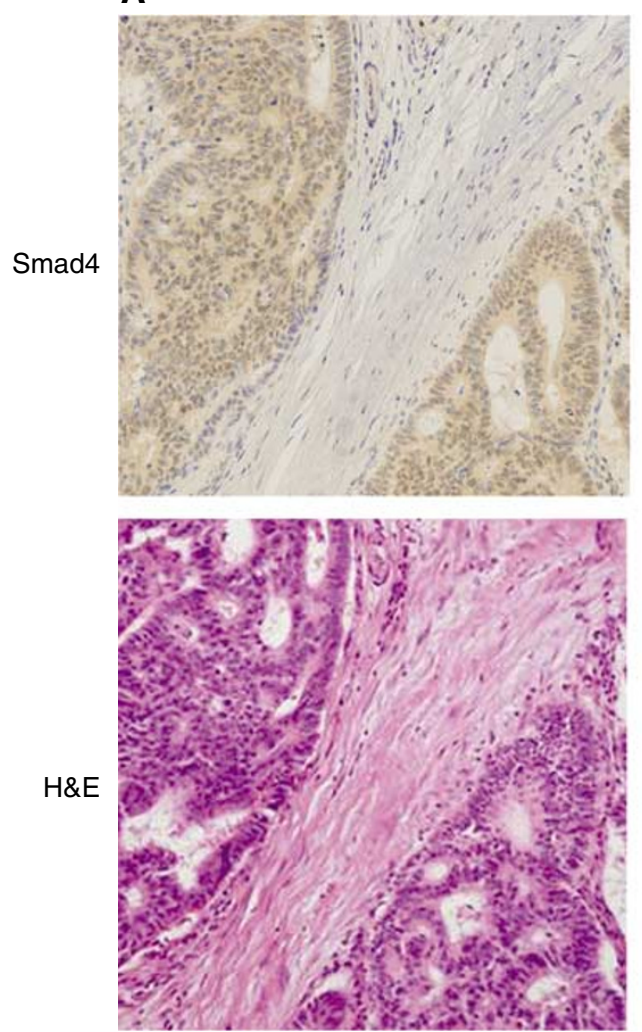

Figure I SMAD4 immunohistochemical staining of colorectal samples. immunohistochemical staining. HE: corresponding samples of H\&E staining.

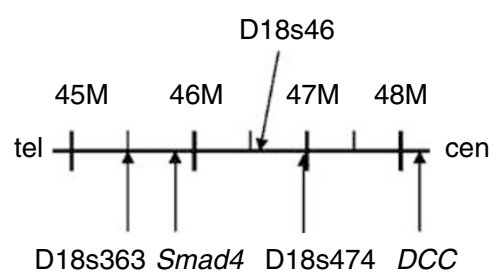

Figure 2 Schematic representation of the microsatellite markers analysed at $|8 q 2|$.

D18s474: 5'-TGGGGTGTTTACCAGCATC-3' (sense), 5'-TGGCTTT CAATGTCAGAAGG- $3^{\prime}$ (antisense); D18s46: $5^{\prime}$-GAATAGCAGGACC TATCAAAGAGC-3' (sense), 5'-CAGATTAAGTGAAAACAGCATAT GTG-3'(antisense). Each primer pair was end-labelled with fluorochrome 6-caboxyl-fluorescein (FAM), 4,7, $2^{\prime}, 4^{\prime}, 5^{\prime}, 7^{\prime}$-hexachloro-6-carboxylfluorescein (HEX) or NED (Applied Biosystems, Tokyo, Japan).

Polymerase chain reaction (PCR) was performed in $10 \mu \mathrm{l}$ reaction volumes containing $10 \times$ PCR Gold Buffer (Applied Biosystems, Tokyo, Japan), $2.5 \mathrm{~mm} \mathrm{MgCl}_{2}, 200 \mu$ l deoxynucleotide triphosphates mixture, $0.5 \mu \mathrm{M}$ of each primer, $20-40 \mathrm{ng}$ of extracted DNA and $0.4 \mathrm{U}$ of AmpliTaq Gold DNA polymerase (Applied Biosystems, Foster City, CA, USA). The DNA was amplified in a thermal cycler (Gene Amp PCR system 9700, Applied Biosystems) and PCR was performed according to the following protocol: $10 \mathrm{~min}$ at $95^{\circ} \mathrm{C}$ for polymerase activation; 40 cycles at $94^{\circ} \mathrm{C}$ for $30 \mathrm{~s}, 56^{\circ} \mathrm{C}$ for $1 \mathrm{~min}$ and $72^{\circ} \mathrm{C}$ for $1 \mathrm{~min}$; then, an additional $30 \mathrm{~min}$ at $70^{\circ} \mathrm{C}$. After denaturization at $95^{\circ} \mathrm{C}$ for $5 \mathrm{~min}$, the PCR products were electrophoresed and analysed on an

\section{C}
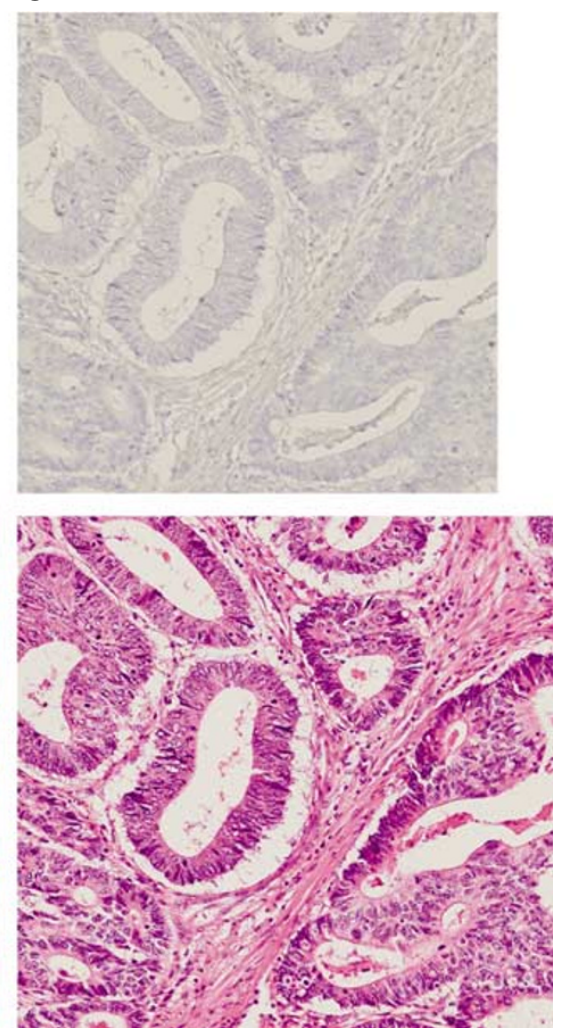
B) low Smad4, (C) no Smad4. Samd4: Smad4

(A) high Smad4,
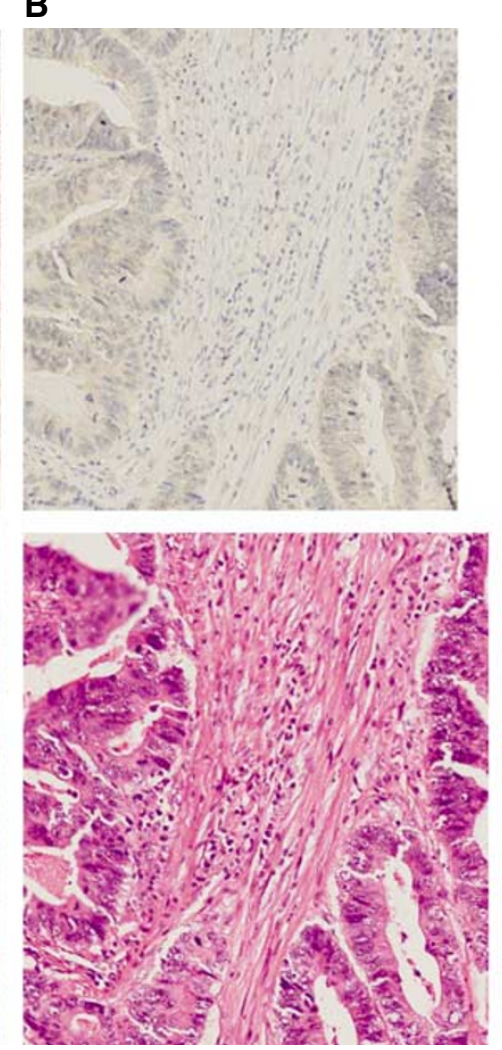


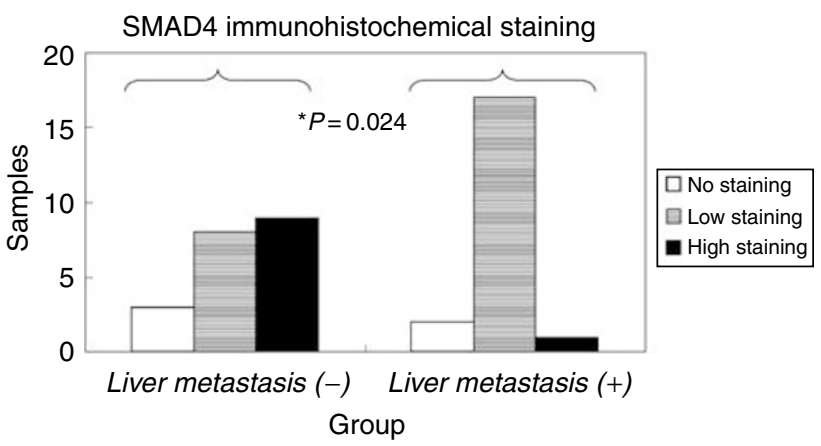

Figure 4 SMAD4 immunohistochemical staining of colorectal tumours. liver-metastasis (-): a group of tumours without liver metastasis. livermetastasis $(+)$ : a group of tumours with liver metastasis.

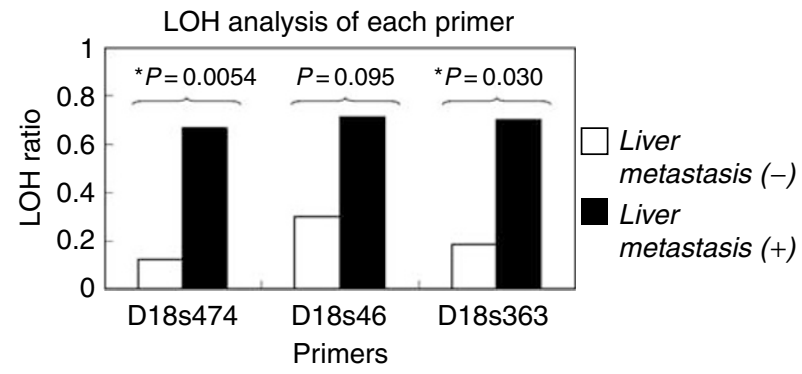

Figure 5 Loss of heterozygosity patterns of each primer. liver-metastasis $(-)$ : a group of tumours without liver metastasis. liver-metastasis $(+)$ : a group of tumours accompanying liver metastasis.

\section{RESULTS}

\section{Immunochemical staining of Smad4 protein}

The results of immunohistochemical staining of Smad4 protein are shown in Figure 4.

In liver-metastasis (-) group, nine cases (45\%) were classified as high Smad4, eight $(40 \%)$ as low Smad4 and three $(15 \%)$ as no Smad4. In liver-metastasis $(+)$ group, only one case $(5 \%)$ was classified as high Smad4, while 17 cases $(85 \%)$ were classified as low Smad4 and two (10\%) as no Smad4. In other words, more cases showed decreased intensity for Smad4 immunohistochemical staining in liver-metastasis (+) group compared to livermetastasis (-) group.

We statistically compared the liver-metastasis $(+)$ and livermetastasis (-) groups from the standpoint of Smad4 protein immunohistochemical staining and found that Fisher's exact test showed a significant difference between both the groups $(P=0.024)$.

\section{Analysis of LOH status of Smad4}

The results for individual primers are shown in Figure 5. The $\mathrm{LOH}$ ratio was defined as the number of $\mathrm{LOH}$ cases divided by all the informative cases in each primer. No cases in this study showed microsatellite instability.

For D18s474, 28 out of 40 cases were informative. The $\mathrm{LOH}$ ratios were $13 \%$ (two out of 16 ) in the liver-metastasis (-) group and $67 \%$ (eight out of 12) in the liver-metastasis (+) group. Fisher's exact test showed that the cases in liver-metastasis (+) group showed significantly higher ratio of allelic loss at D18s474 compared with those in liver-metastasis $(-)$ group $(P=0.0054)$. For D18s46, 24 out of 40 cases were informative, and the $\mathrm{LOH}$

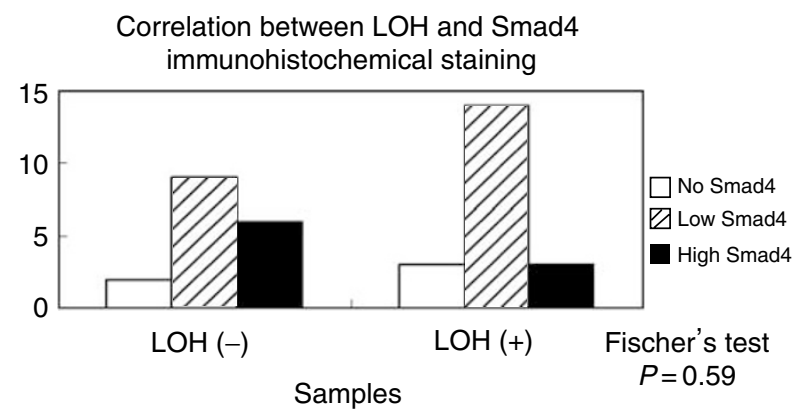

Figure 6 Correlation between $\mathrm{LOH}$ and Smad4 immunohistochemical staining.

ratios were $30 \%$ (three out of 10 ) in the liver-metastasis (-) group vs $71 \%$ (10 out of 15$)$ in the liver-metastasis (+) group, with no significant difference $(P=0.095)$ found between the groups. For the primer D18s363, 21 out of 40 cases were informative, and 18\% (two out of 11) of the cases demonstrated $\mathrm{LOH}$ in the livermetastasis (-) group vs $70 \%$ (seven out of 10) in the livermetastasis $(+)$ group. This result showed a statistically significant difference $(P=0.030)$

\section{Correlation between $\mathrm{LOH}$ at chromosome 18q21 and Smad4 immunohistochemical staining}

We then examined if $\mathrm{LOH}$ at chromosome 18q21 had a direct effect on Smad4 protein level in 40 samples (Figure 6). Those samples that showed allelic loss in any of these three primers were classified positive for LOH. The samples in liver-metastasis (+) group showed more cases of low Smad4 compared to liver-metastasis (-) group, although statistical analysis did not show a significant difference $(P=0.59)$.

\section{DISCUSSION}

In the current study, we selected only lymph node negative cases and matched for T-classification, tumour locations and tumour differentiations between liver-metastasis $(+) /(-)$ groups, and demonstrated significant statistical differences between these two groups in Smad4 protein level and chromosome 18q deletion. This is the first report to focus on the specific impact of liver metastasis on Smad4 protein expression and chromosome $18 \mathrm{q}$ deletion with clinical features other than liver metastasis being matched. Decreases in Smad4 protein expression and chromosome 18q deletion are known to be characteristic risk factors of liver metastasis.

It has been proven that the loss of chromosome 18q, which is present in about $70 \%$ of colorectal cancers, is related to tumour progression, recurrence and poor prognosis. Jen et al (1994) reported that patients with stage II colorectal cancer and chromosome 18q allelic loss show worse prognosis than those without $18 \mathrm{q}$ allelic loss. They pointed out that stage II colorectal cancer patients with $18 \mathrm{q}$ allelic loss have a similar prognosis to stage III patients. Moreover, they argued that stage II colorectal cancer patients without $18 \mathrm{q}$ allelic loss show similar prognosis to those with stage I patients. A study by Lanza et al (1998) also showed similar results in that patients with stage II disease whose tumour had no $18 \mathrm{q}$ allelic loss demonstrated a 5-year survival rate of $96 \%$, while those with stage II disease and 18q allelic loss showed a 5-year survival rate of only $54 \%$. Ogunbiyi et al (1998) reported that Chromosome $18 \mathrm{q}$ allelic loss was significantly associated with reduced disease-free and disease-specific survival in patients with stage II $(P=0.05$ and $P=0.0156)$ and III disease $(P=0.038$ and $P=0.032$ ). We showed that microsatellite stable (MSS) patients with stage III colorectal cancer showed poor 
prognosis when chromosome $18 \mathrm{q}$ showed allelic loss $(P=0.006)$ (Watanabe et al, 2001). We also recently argued that 18q allelic loss is a significant prognostic value in colorectal cancer (Watanabe et al, 2006).

In the current study, we demonstrated that there was a significant statistical association of chromosome $18 \mathrm{q}$ deletion with liver metastasis, which has a strong impact on survival after surgery. This study was the first to evaluate the influence on liver metastasis of $18 \mathrm{q}$ deletion where tumour depth, lymph node invasion, tumour differentiation and tumour location were excluded, and confirmed that $18 \mathrm{q}$ allelic loss is a useful marker of liver metastasis.

There have been numerous efforts to detect the target genes at chromosome $18 \mathrm{q}$ in colorectal carcinogenesis and cancer progression, and two putative genes have been detected. The DCC gene located at $18 \mathrm{q} 21$ was first considered to be an important target gene and to play an important role in colorectal pathogenesis (Fearon et al, 1990; Shibata et al, 1996). However, there have been several cases with $18 \mathrm{q}$ deletion in which no inactivation of $D C C$ was observed, implying the existence of another target gene (Cho et al, 1994). Subsequently, Smad4 gene was detected as another target at 18q21.1, whose mutations were detected up to $35 \%$ of colorectal cancers (Shibata et al, 1996).

In a previous study, the genomic inactivation of Smad4 was reported to correlate with carcinogenesis, tumour progression and poorer prognosis in colorectal caners. Miyaki et al (1999) reported that they found no Smad4 mutation in adenomas and intramucosal carcinomas, although the frequency of the mutation increased as the invasiveness of the tumour grew. Furthermore, they found a higher frequency of mutation in colorectal cancers with distant metastasis compared to those without distant metastasis. Their study strongly indicated that the Smad4 gene correlates with malignancy in the advanced stage and is the target gene on
$18 \mathrm{q} 21.1$, the locus indicative of tumour progression and poorer prognosis when deleted.

Recently, an immunohistochemical assay of Smad4 protein has been developed and several studies indicated that Smad4 protein inactivation affected survival. Anirban Maitra et al classified patients according to TNM stage and examined Smad4 protein expression for the first time. In their study, they found no Smad4 protein inactivation in stage I patients, $8 \%$ in stage II, $6 \%$ in stage III and $22 \%$ in stage IV patients, indicating that tumour progression correlates with Smad4 protein inactivation. They also classified patients into two groups according to the status of liver metastasis, and indicated a borderline significant correlation between Smad4 staining and liver metastasis $(P=0.05)$ (Maitra et al, 2000). Alazzouzi et al (2005) studied 86 Dukes' C colorectal cancer patients and showed that patients with Dukes' C tumours expressing high Smad4 protein levels had significantly better overall $(P<0.025)$ and disease-free $(P<0.013)$ survival than patients with low levels by immunohistochemical staining. We, too, recently discussed the association between Smad4 level and prognosis in colorectal cancers. Previous reports suggested that Smad4 protein inactivation correlates with liver metastasis; however, the groups consisted of various $\mathrm{T}$ - and $\mathrm{N}$-stage patients.

In this study, lymph node negative cases were matched for Tclassification, tumour depth and tumour location and demonstrated a statistically significant difference $(P=0.024)$ in Smad4 protein expression level between liver-metastasis $(+) /(-)$ groups. This result confirmed more accurately the previous report that Smad4 protein inactivation is related to the process or the risk of liver metastasis.

In conclusion, our results showed that both chromosome $18 \mathrm{q}$ deletion and Smad4 protein expression are associated with liver metastasis in colorectal cancers, and that they both play an important role in the development of liver metastasis.

\section{REFERENCES}

Alazzouzi H, Alhopuro P, Salovaara R, Sammalkorpi H, Jarvinen H, Mecklin JP, Hemminki A, Schwartz Jr S, Aaltonen LA, Arango D (2005) SMAD4 as a prognostic marker in colorectal cancer. Clin Cancer Res 11: 2606-2611

Benhattar J, Losi L, Chaubert P, Givel JC, Costa J (1993) Prognostic significance of K-ras mutations in colorectal carcinoma. Gastroenterology 104: $1044-1048$

Carethers JM, Hawn MT, Greenson JK, Hitchcock CL, Boland CR (1998) Prognostic significance of allelic lost at chromosome $18 \mathrm{q} 21$ for stage II colorectal cancer. Gastroenterology 114: 1188-1195

Cho KR, Oliner JD, Simons JW, Hedrick L, Fearon ER, Preisinger AC, Hedge P, Silverman GA, Vogelstein B (1994) The DCC gene: structural analysis and mutations in colorectal carcinomas. Genomics 19: $525-531$

Chung DC (1998) Molecular prognostic markers and colorectal cancer: the search goes on. Gastroenterology 114: 1330-1332

Eppert K, Scherer SW, Ozcelik H, Pirone R, Hoodless P, Kim H, Tsui LC, Bapat B, Gallinger S, Andrulis IL, Thomsen GH, Wrana JL, Attisano L (1996) MADR2 maps to 18q21 and encodes a TGFbeta-regulated MADrelated protein that is functionally mutated in colorectal carcinoma. Cell 86: $543-552$

Fearon ER, Cho KR, Nigro JM, Kern SE, Simons JW, Ruppert JM, Hamilton SR, Preisinger AC, Thomas G, Kinzler KW, Vogelstein B (1990) Identification of a chromosome $18 \mathrm{q}$ gene that is altered in colorectal cancers. Science 247: 49-56

Fink SP, Mikkola D, Willson JK, Markowitz S (2003) TGF-beta-induced nuclear localization of Smad2 and Smad3 in Smad4 null cancer cell lines. Oncogene 22: $1317-1323$

Hahn SA, Schutte M, Hoque AT, Moskaluk CA, da Costa LT, Rozenblum E, Weinstein CL, Fischer A, Yeo CJ, Hruban RH, Kern SE (1996) DPC4, a candidate tumor suppressor gene at human chromosome 18q21.1. Science 271: $350-353$

Iacobuzio-Donahue CA, Klimstra DS, Adsay NV, Wilentz RE, Argani P, Sohn TA, Yeo CJ, Cameron JL, Kern SE, Hruban RH (2000) Dpc-4 protein is expressed in virtually all human intraductal papillary mucinous neoplasms of the pancreas: comparison with conventional ductal adenocarcinomas. Am J Pathol 157: 755-761

Jen J, Kim H, Piantadosi S, Liu ZF, Levitt RC, Sistonen P, Kinzler KW, Vogelstein B, Hamilton SR (1994) Allelic loss of chromosome 18q and prognosis in colorectal cancer. N Engl J Med 331: 213-221

Jernvall P, Makinen MJ, Karttunen TJ, Makela J, Vihko P (1999) Loss of heterozygosity at $18 \mathrm{q} 21$ is indicative of recurrence and therefore poor prognosis in a subset of colorectal cancers. $\mathrm{Br} \mathrm{J}$ Cancer 79: $903-908$

Kambara T, Sharp GB, Nagasaka T, Takeda M, Sasamoto H, Nakagawa H, Isozaki H, MacPhee DG, Jass JR, Tanaka N, Matsubara N (2004) Allelic loss of a common microsatellite marker MYCL1: a useful prognostic factor of poor outcomes in colorectal cancer. Clin Cancer Res 10: 1758 1763

Kazama Y, Watanabe T, Kanazawa T, Kazama S, Tada T, Tanaka J, Nagawa H (2006) Mucinous colorectal cancers with chromosomal instability: a biologically distinct and aggressive subtype. Diagn Mol Pathol 15: 30-34

Kinzler KW, Vogelstein B (1996) Lessons from hereditary colorectal cancer. Cell 87: $159-170$

Lanza G, Matteuzzi M, Gafa R, Orvieto E, Maestri I, Santini A, del Senno L (1998) Chromosome $18 \mathrm{q}$ allelic loss and prognosis in stage II and III colon cancer. Int J Cancer 79: $390-395$

Li F, Cao Y, Townsend Jr CM, Ko TC (2005) TGF-beta signaling in colon cancer cells. World J Surg 29: $306-311$

Maitra A, Molberg K, Albores-Saavedra J, Lindberg G (2000) Loss of Dpc4 expression in colonic adenocarcinomas correlates with the presence of metastatic disease. Am J Pathol 157: 1105-1111

Markowitz S (2000) TGF-beta receptors and DNA repair genes, coupled targets in a pathway of human colon carcinogenesis. Biochim Biophys Acta 1470: M13-M20

McLeod HL, Murray GI (1999) Tumour markers of prognosis in colorectal cancer. Br J Cancer 79: 191-203 
Miyaki M, Iijima T, Konishi M, Sakai K, Ishii A, Yasuno M, Hishima T, Koike M, Shitara N, Iwama T, Utsunomiya J, Kuroki T, Mori T (1999) Higher frequency of Smad4 gene mutation in human colorectal cancer with distant metastasis. Oncogene 18: 3098-3103

Nassif NT, Lobo GP, Wu X, Henderson CJ, Morrison CD, Eng C, Jalaludin B, Segelov E (2004) PTEN mutations are common in sporadic microsatellite stable colorectal cancer. Oncogene 23: 617-628

Ogunbiyi OA, Goodfellow PJ, Herfarth K, Gagliardi G, Swanson PE, Birnbaum EH, Read TE, Fleshman JW, Kodner IJ, Moley JF (1998) Confirmation that chromosome $18 \mathrm{q}$ allelic loss in colon cancer is a prognostic indicator. J Clin Oncol 16: 427-433

Sarli L, Bottarelli L, Bader G, Iusco D, Pizzi S, Costi R, D’Adda T, Bertolani M, Roncoroni L, Bordi C (2004) Association between recurrence of sporadic colorectal cancer, high level of microsatellite instability, and loss of heterozygosity at chromosome 18q. Dis Colon Rectum 47: 1467-1482

Shibata D, Reale MA, Lavin P, Silverman M, Fearon ER, Steele Jr G, Jessup JM, Loda M, Summerhayes IC (1996) The DCC protein and prognosis in colorectal cancer. $N$ Engl J Med 335: 1727-1732

Span M, Moerkerk PT, De Goeij AF, Arends JW (1996) A detailed analysis of $K$-ras point mutations in relation to tumor progression and survival in colorectal cancer patients. Int J Cancer 69: 241-245
Thiagalingam S, Lengauer C, Leach FS, Schutte M, Hahn SA, Overhauser J, Willson JK, Markowitz S, Hamilton SR, Kern SE, Kinzler KW, Vogelstein B (1996) Evaluation of candidate tumour suppressor genes on chromosome 18 in colorectal cancers. Nat Genet 13: 343-346

Vogelstein B, Fearon ER, Hamilton SR, Kern SE, Preisinger AC, Leppert M, Nakamura Y, White R, Smits AM, Bos JL (1988) Genetic alterations during colorectal-tumor development. $N$ Engl J Med 319: $525-532$

Vogelstein B, Fearon ER, Kern SE, Hamilton SR, Preisinger AC, Nakamura Y, White R (1989) Allelotype of colorectal carcinomas. Science 244: $207-211$

Wang CY, Eshleman JR, Willson JK, Markowitz S (1995) Both transforming growth factor-beta and substrate release are inducers of apoptosis in a human colon adenoma cell line. Cancer Res 55: 5101-5105

Watanabe T, Kanazawa T, Kazama Y, Tanaka J, Tanaka T, Ishihara S, Nagawa H (2006) SMAD4 levels and allelic imbalance in 18q21 in colorectal cancer. Clin Cancer Res 12: 1654 author reply 1654-1655

Watanabe T, Wu TT, Catalano PJ, Ueki T, Satriano R, Haller DG, Benson III AB, Hamilton SR (2001) Molecular predictors of survival after adjuvant chemotherapy for colon cancer. $N$ Engl $J$ Med 344: $1196-1206$ 